\title{
Wayfinding Techniques at Common First Year King Saud University - An Indoor Localization Approach for Navigation
}

\author{
Dr. Wael Mohammad Alenazy ${ }^{a}$ \\ a Assistant Professor,Self-Development Skills Department,'Computer Skills',Common First Year Deanship, King Saud \\ University,, Riyadh, KSA
}

Article History: Received: 10 November 2020; Revised 12 January 2021 Accepted: 27 January 2021; Published online: 5 April 2021

\begin{abstract}
The development of ICT technologies in recent years has shown remarkable changes with the internet of things and smart gadgets. This presented an opportunity for indoor navigation to develop a system for indoor positioning systems, such as GPS, that can assist any beneficiary in navigating inside the building and locating themselves. This paper focuses on the educational sector, specifically in King Saud University's Common First Year. To fit the educational setting, a detailed study using various techniques was reviewed. Overall, a meta-analysis was completed that will aid in the implementation of the sensors nodes technique in the future as a prototype on Common First Year campuses.
\end{abstract}

Keywords: Indoor localization(IL), Sensors Nodes, GPS , ICT

\section{Introduction}

Indoor localization has become more important in recent years. Indoor Localization (IL) or Indoor Positioning Systems (IPS) is best described as a GPS for indoor environments. Smart gadgets such as smart phones, tablets, and wearable devices such as smart watches, rings, bracelets, and smart glass for the disabled can be used to locate people or objects inside buildings. Although the technology is newer than GPS, indoor localization services are quickly gaining traction in a variety of large-scale institutions. The current papers represent a review of methods focusing on educational campuses. It is divided into several sections, each of which provides detailed information about the background study and various techniques used in various locations. The methodology section explains the current scenario of the common first-year orientation day, in which students are frequently confused as to where they should go for various events to attend during the orientation day.

\section{Background of Indoor Localization Approaches}

In recent years, cutting-edge related technologies have been extensively utilized. Smartphones are now capable of providing location-based information using a variety of sensors and modern techniques such as GPS, Wi-Fi, and Bluetooth. [two] There is a high social and technological demand for personal location-based services that work in places where GPS is unavailable. (3). Because GPS signals do not pass through roofs and walls, GPS does not work inside buildings. Due to interference and Line of Sight (LOS) issues, GPS works with low accuracy even in thin areas. [number four]

\subsection{Approaches based on traditional radio technology:}

For more than a decade, a variety of technologies have been investigated for indoor positioning. Traditional radio signals, such as Wi-Fi, Cellular Network, Bluetooth, FM radio, and RFID, are the most well-known approaches. The location of a target in the environment can be estimated using these wireless technologies by measuring one or more properties of the electromagnetic wave emitted by transmitters and received by the target. Angle of Arrival (AoA), Time of Arrival (ToA) or Time Difference of Arrival (TDoA), and Radio Signal Strength (RSS) fingerprinting have all been extensively investigated so far.

Using low-power off-the-shelf 802.11n multiple APs, a study titled "Multi-Site Fusion for WLAN Based Indoor Localization via Maximum Discrimination Fingerprinting"[5] was conducted.

The offline database construction phase, where RSS mapping is performed, is the first phase of the two-phase technique. They then extracted the corresponding fingerprints for each AP on that map using the Channel Frequency Reference covariance matrix and the Maximum Discrimination Projection method, and built fingerprint databases and similarity profiles databases. In the online User localization phase, the RSS mapping is used to determine which $\mathrm{AP}(\mathrm{s})$ are covering the unknown location, and then each covering AP obtains the CFR 
covariance matrix for that location (s). The correct location is then determined using either single or fusion similarity profile matching.

They created fingerprints using the envelope of the Long Training Field (LTF) of the preamble of the 802.11a/g/n Wi-Fi packet and a special purpose array antenna transmitter with high power capabilities for single site localization. To improve localization performance, they combined pre-existing infrastructure with accurate information provided by the Channel Frequency Response (CFR). They claimed and achieved metre level accuracy using the aforementioned method.

DeepFi[6], a deep learning-based indoor fingerprinting scheme that uses Channel State Information, is undergoing research in a similar vein (CSI). The device driver collects CSI for all subcarriers and antennas in this method, which is then analysed with a deep network.

To obtain the estimated location, the DeepFi system architecture includes an offline training phase and an online localization phase using a probabilistic method based on the radial basis function. Deep learning is used in the offline training phase to train all the weights of a deep network as fingerprints, and a greedy learning algorithm is incorporated layer by layer for weight training to reduce complexity..

According to the study, a deep-learning-based fingerprinting scheme could be used to overcome the limitations of existing machine-learning-based methods. The deep-learning-based method can fully explore the features of wireless channel data and produce the best weights as fingerprints. To reduce computational complexity, it also includes a greedy learning algorithm. The study uses CSI to obtain more fine-grained wireless channel information than RSS-based schemes, such as the amplitude and phase of each subcarrier from each antenna for each received packet. They claimed and achieved metre level accuracy using the aforementioned method.

Hossain [7] discussed a different aspect of fingerprint-based location systems with enhanced accuracy in a study based on Multiple Wireless Technologies. They claimed to have developed a robust location fingerprint definition using a weighted linear regression technique that combined signals from multiple wireless technologies. It proved to be a better fit for fictitious training points, taking advantage of signal strength distribution spatial similarity.

Using Bluetooth and Wi-Fi signals together, the study suggested two well-known localization algorithms, KNearest Neighbor and Bayesian Probabilistic Model. SSD - Signal Strength Difference perceived at APs provides a more robust location fingerprint than absolute signal strength values by itself, according to research[8], and increasing the number of APs does not always increase the localization accuracy monotonically. [nine] They also discovered that when using an SSD as a location fingerprint, Bluetooth outperforms Wi-Fi in every situation.

An intelligent method for information integration is required to achieve the goal of having an accurate, alwaysavailable, and simple-to-compute pedestrian positioning solution. Mohammad Bhuiyan's research, titled Using Building Layout for Performance Optimization of a Multi-Sensor Fusion Model in Indoor Navigation, used a Kalman Filter-based fusion model to combine Wi-Fi fingerprints, super sensitive GPS readings, and data from IMUs. The fusion filter improved positioning accuracy while also increasing positioning availability. Inside a typical office building, the KF-based fusion model achieves a horizontal accuracy of around 6 metres, and with the building layout information, it improves horizontal position accuracy to around 4.95 metres. This provided a first look at the kind of performance that can be achieved with low-cost heterogeneous location, heading, and speed observations aided by building layout information. [9]

Inertial Measurement Units (IMUs) are built into today's smart devices and smartphones, allowing them to send and receive data or information via radio signals on their own. To achieve high accuracy and stable performance in the tracking process, a study on real-time robust indoor tracking system in smartphones proposed fusing RSS, IMU, and floor map in an enhanced particle filter. They were able to reduce the errors caused by magnetic field disturbances and inaccurate off-the-shelf IMUs by using a stochastic model for location estimation and effective filtering of IMU readings. To mitigate the errors caused by the low Wi-Fi sampling rate and make the system fault tolerant, a double re-sampling method was used.

Through an automatic localization failure recovery mechanism, improved PDR measurements (by considering magnetic field and angular velocity through Direction Cosine Matrix filter), and the implementation of a graph based model to describe the physical environment, the research attempted to provide a solution for major issues in localization failures such as global localization problem and kidnapped robot problem. The results showed that the tracking method can automatically recover from failures in localization. The average tracking error in the evaluation experiment was 1.15 metres, with a standard deviation of 0.8 metres. [9]

Indoor pedestrian localization with multi-sensor information fusion strain upon particle filter algorithm based on multi-sensor fusion was studied by Xianguy $\mathrm{Xu}[12]$. The algorithm combines the smart mobile terminal with 
indoor localization and uses a particle filter to filter the results of the localization. To improve the filtering precision and stability, they used a PDR-based dynamic interval particle filter algorithm and RSSI localization information. The study focused on a particle filter algorithm that combines multi-sensor fusion with IMU readings. The user's movement is recorded by the IMU, and Bayesian estimates of the $\mathrm{m}$ are madeWhen compared to a location algorithm based on Wi-Fi, experimental results show that the multi-sensor algorithm improves localization accuracy and robustness. The proposed method has an average error of over 0.35 metres in a $21 \mathrm{~m} \mathrm{X}$ $18 \mathrm{~m}$ area, which is better than the location algorithm based solely on Wi-Fi, which has an average error of 1.65 metres. (If the user is moving, the research found an error of $0.54 \mathrm{~m}$ and $2.35 \mathrm{~m}$, respectively.)

Jeong et al. [13] proposed the Smartphone-Assisted Localization Algorithm (called SALA) for positioning indoor IoT devices, which allows the smartphone to visually display the positions of IoT devices in indoor environments. In this case, the smartphone acts as a mobile beacon that uses a sensor-fusion method to track its own position indoors using its various built-in sensors.

The study focused on a smart home in which a moving smartphone broadcasts short-range beacon messages on a regular basis and collects responses from nearby IoT devices. The response usually includes information about IoT devices. For localization, the smartphone saves this response, along with the RSS and its location, to a dedicated server. The closer the distance between two devices, the stronger the RSS of the exchanged message frame, according to SALA. The sample points with the received signal strength are analysed to determine the best grid position for the IoT device (using power map algorithm and grid-weight map algorithm). Offline, along with a given indoor layout, these stored trace data is processed.

According to the study, SALA can effectively localiseIoT devices with position errors of less than $20 \mathrm{~cm}$ during simulations (in $8.7 \mathrm{~m} \mathrm{x} 6.6 \mathrm{~m}$ area). The average collective motion error in the real experiment, however, was more than $195 \mathrm{~cm} .[13]$

The proposed approach shows an error of 0.07 percent for the total travelled distance after introducing an implementation for PDR algorithm using 6-D vectors (3-axis acceleration and 3-axis magnetic field) QuaternionBased Extended Kalman filter for heading estimation with Low Pass filter and adaptive step length methodology. (\#14)

Another research paradigm with a similar baseline discussed the design and implementation of an Internet of Things (IoT)-based indoor localization system using Bluetooth Low Energy (BLE) technology[15][16][17]. They used different modules like data measurement through Bluetooth[18] beacons, data aggregation and transmission, storage, web-interface and cloud services for data, and results visualisation with the help of two key intrinsic components, an acquisition system and a central server. The proposed system's localization mechanism was based on a location algorithm derived from the Received Signal Strength (RSS) footprinting method, which enabled it to detect reference zones within closed environments.

The system proposed a general architecture (designed from an IoT modular standpoint) for identifying reference stations in indoor environments, with two main systems: Acquisition and Central Server. The acquisition system is in charge of acquiring RF signals and performing RSS identification using BLE Technology[19], whereas the Central Server implements a local storage database and a local web interface to display the raw and processed data stored in the database.

In closed environments, the BLE technology has propagation properties that allow it to determine proximity and distance values with some error. Many physical properties of such environments, such as the multipath effect, scattering, and the complexity and dynamic of interior structures, have a negative impact on signal radio propagation. Using custom software at the data aggregation stage of the acquisition system, the proposed approach yields a final error of $29.8 \%$ [15].Jesus LovonMelgarejo et al[17] used two supervised learning algorithms, SVM and k-NN, to develop beacon-based location mechanisms with a similar setup. They argue that, in comparison to $\mathrm{SVM}$, the use of the k-NN algorithm may be more effective in developing an indoor location fingerprinting mechanism (though BLE signals are susceptible to fast fading impairments, making it difficult to measure RSSI to develop Wi-Fi based fingerprinting). Despite this, the experiment was unable to achieve meter-level accuracy.

Localization systems with a 1 metre accuracy could be used for navigating complex facilities and locating specific locations, people, or objects. The same is discussed in the Bluetooth Indoor Localization System based on the 'Incorrectly Triangulation System.' [20] a Using a dedicated cross correlation chip, the proposed trilaterationbased system measures the RF signal propagation time with 3 nanosecond accuracy using the Differential Time Difference of Arrival - DTDoA method. The system calculates the distance between two points of unknown position by measuring the propagation time of an electromagnetic wave. They used additional hardware on the base stations, whereas no additional hardware was required in mobile. The aforementioned research could achieve metre position accuracy with a simplified demonstration setup. [20] A study published by the Spanish Council for Scientific Research [21] on Smartphone-Based Cooperative Indoor Localization with RFID Technology [22] 
discusses the localization and tracking of people using smartphones by combining RSS emitted from known location beacons with PDR, which estimates user motion.

To improve overall positioning accuracy, the study recommended a centralised cooperative particle filter (PF) formulation over the joint state of all users that allows for the processing of RSS measurements from both anchor and mobile emitters, as well as PDR motion estimates and map information. Sensor measurements, low-level processing, and data transmission to a central unit, where cooperative localization took place, were all handled by smartphones.

The study found that when limited users moved in an area with active RFID tags, their individual localization improved in terms of positioning accuracy each time they used cooperative PF, PDR, and map information, respectively.

A study led by Hammadi at Khalifa University on Indoor Localization and Guidance Using Portable Smartphones describes an android-based indoor map guidance system that assists and guides delegates inside an academic setting such as a university. It was concentrating on using low-cost Near Field Communication - NFC (RFID is the process of uniquely identifying items using radio waves, and NFC is a specialised subset of RFID technology). NFC (Near Field Communication) is a low-cost wireless technology with short-range communication capability and a branch of High-Frequency (HF) RFID, both of which operate at the $13.56 \mathrm{MHz}$ frequency.) technology and Quick Response QR Codes with Dijkstra algorithm to determine the location and provide navigation within the university. Researchers developed a system that relies on a server that contains three mail parts: a web server, a map server, and a spatial database, all of which are open source and freely available software

According to the study, NFC tags should be scattered throughout the premises in known locations, allowing users to determine the location of a device that scans those tags.[page 24] It uses the Dijkstra algorithm to calculate the shortest path from the current location to the desired destination after receiving the user's current location and desired destination. Due to the fixed positions of the NFC tags, higher accuracy can be achieved. [No. 25]

The bilingual app could also be used to find a destination, calculate the shortest path, locate car parking, and provide feedback to building management, among other things.

\subsection{Light \& Sound Based Approaches:}

Indoor localization solutions with the desired simplicity, robustness, accuracy, and responsiveness are still needed for IoT applications. Shang Ma discusses Foglight, a visible light-based indoor localization system that allows low-power IoT devices to pinpoint their location with sub-centimeter accuracy [26].

When mechanical mirrors inside a projector are flipped based on gray-coded binary images, it creates a unique spatial encoding. This image encodes each pixel within the projection area in a unique way, allowing IoT devices to collect and decode a sequence of light intensity and recognise their own position within the projection area. It employs a low-cost, battery-operated TAOS \& TSL13T off-the-shelf light sensor that can easily be coupled with such devices to achieve high-accuracy localization with minimal signal processing overhead, low latency, and low power consumption.

The entire system is energy efficient, making it suitable for low-power IoT devices and long-term deployment for large-scale applications. It achieves sub-centimeter precision in fine-grained localization. This opens up a wide range of new applications in which high-accuracy location is required.

Foglight can locate a target device with an average accuracy of 1.7 millimetres in a controlled lab study, with an average refresh rate of $84 \mathrm{~Hz}$ and a minimal latency of 31.46 milliseconds on $\mathrm{Wi}-\mathrm{Fi}$ and 23.2 milliseconds on serial communication. However, the requirement for line-of-sight is the method's most significant limitation. It can only locate devices within the projection area, so using it in a larger area could be difficult!

A precise localization system is required to implement a reliable and efficient solution to assist frail people with a continuous and consistent form of information for safe exploitation of indoor environments. The importance of ultrasound-based localization systems among the various technologies is highlighted in a study conducted by the University of Catania in Italy on Smart MultiSensor Strategies for Indoor Localization[27]. It believes that by installing a sensor network in the environment, the highest accuracy can be achieved.

Wireless Sensor Network and Advanced Signal Processing are used in the system. User Environment Interaction (UEI) and User-Environment-Contextualization improve location accuracy even more (UEC). Within the Wireless Network, it primarily works on two things: environment nodes and user nodes. Environment nodes 
are equipped with various sensors, including ultrasound sensors, to implement the user localization task. To monitor the status, the user must wear a wearable with an embedded inertial sensor.

The ultrasound localization system works by continuously measuring distances between the user and the nodes in the environment. By measuring and processing four successive ultrasound impulses, it uses an Anti-Bouncing Filter $(\mathrm{ABF})$ to reduce bouncing effects in the estimation of ToAs. For user localization, the resulting ToAs are converted to distances and sent to the Multi-Trilateration Algorithm (MTA). MTA is more time-consuming than the traditional Trilateration Algorithm, but it is unquestionably recommended for extremely accurate indoor localization tasks. The said research was able to achieve an accuracy of better than $4 \mathrm{~cm}$ in an environment of 8.60 $\mathrm{m}$ by $7.10 \mathrm{~m}$, with seven nodes roughly positioned at a height of about $3.0 \mathrm{~m}$.

Despite notable efforts in recent years, accurate and practical solutions to indoor localization remain a challenge. Kaikai Liu of the University of Florida proposes the "Guoguo"[28] indoor localization system. The technology that allows users to get centimeter-level location accuracy and integrates with context-aware mobile services has the potential to revolutionise the indoor localization concept.

They devised a workable solution that includes an anchor network with a coordination protocol for transmitting modulated localization beacons over high-band acoustic signals, a real-time processing app for smartphones, and a backend server for indoor contexts and location-based services. The detection sensitivity of imperceptible acoustic beacons is improved, resulting in better location coverage, higher accuracy, and lower power consumption.

Rather than using simple passive beep signals, the system employs the transmission waveform, wide-band modulation, and one-way synchronisation and ranging schemes. To enable anchor node identification without radio assistance on a smartphone, the acoustic beacon transmission scheme uses high-density pseudo-codes. They proposed a symbol interleaved beacon structure to overcome the disadvantage of low acoustic signal transmission speed and increase the location update rate. They proposed a fine-grained adaptive TOA estimation approach that exploits the details of the beacon signal and performs NLOS identification and mitigation to improve ranging accuracy. In the chosen environment, experimental results showed centimeter-level localization accuracy of 6-25 $\mathrm{cm}$.

\subsection{UWB Based Approaches:}

In recent years, the market has begun to pay attention to UWB-based technology for the purpose of indoor localization. The modulation scheme is gaining popularity due to its suitability for such applications. A typical UWB-based system sent data in the form of very narrow nano or sub-nanosecond pulses spread over a frequency range of hundreds of megahertz. Indoor localization systems benefit from this design because short pulses provide sub-nanosecond accuracy in timing measurement of the received UWB signal, which corresponds to centimeterlevel accuracy in distance. It also improves the overall system's resistance to multipath fading, which is still a difficult problem for conventional radio signals in indoor environments due to signal reflection.

As a result of the need to operate in unlicensed bandwidth and the transmit power restriction, we can see that UWB communication has a relatively short effective range. It means that a sufficient number of reference nodes may be required for large-scale deployment, and these nodes must be affordable. UWB receivers consume a lot of power, making them unsuitable for low-power IoT applications. [26.]

\section{Demand for Case Studies}

The challenge of adapting indoor localization in educational campuses is described here with a real-world example from King Saud University's Common First Year.During Orientation Week, students are challenged to place themselves in the correct location. In this case, as shown in fig. 1, indoor localization will allow students to select a simple and comfortable path to various locations. Furthermore, it outlines the various stages of the students' journey from pre-orientation to arriving on campus and participating in various events at various locations

\subsection{CFY's Orientation Day Scenario}

To begin, students must register online using a link from the CFY e-portal, which allows them to schedule their attendance at the orientation programme for a specific week. There are several steps to follow.

1. English level placement test: Students register for an online placement test that is designed to place firstyear students in the appropriate level of English language study.

2. Email Activation: After passing the placement test, the portal will redirect you to your active university email account.

3. Slot Reservation: Choosing a time slot for the orientation day from the available options. 
During orientation week, students are required to attend a variety of events at various locations for activities such as

1. Attending the welcome seminar: Students attend the CFY campus's induction seminar.

2. Student ID Card Collection: Following the seminar, students will be directed to collect their student ID cards.

3. Purchasing Books: After that, the students are in charge of collecting and purchasing the books.

4. Exploring internal society clubs and registering: Students can register for extracurricular activities and explore different clubs.

In the case of CFY's orientation day, the students follow the ordinary path with someone's manpower guidance, which leads to a jumble of students finding themselves in various locations. As a result of the new approach's use of indoor localization, students can easily provide direction using their own smart devices. It will make it easier for them to get to their designated spots in the groups without making any mistakes. This technology will allow students to easily allocate time and space in a reasonable manner.

In this scenario, King Saud University's Common First Year induction programme is depicted. The beneficiaries' difficulties navigating within the campus to various locations are depicted in fig. 1. The use of sensor nodes at various locations, such as Wi-Fi access points, will aid in determining where to interchange from one point to another. Beneficiaries will be able to easily transfer from one location to another using their smart phones or wearable devices as a result of this implementation.

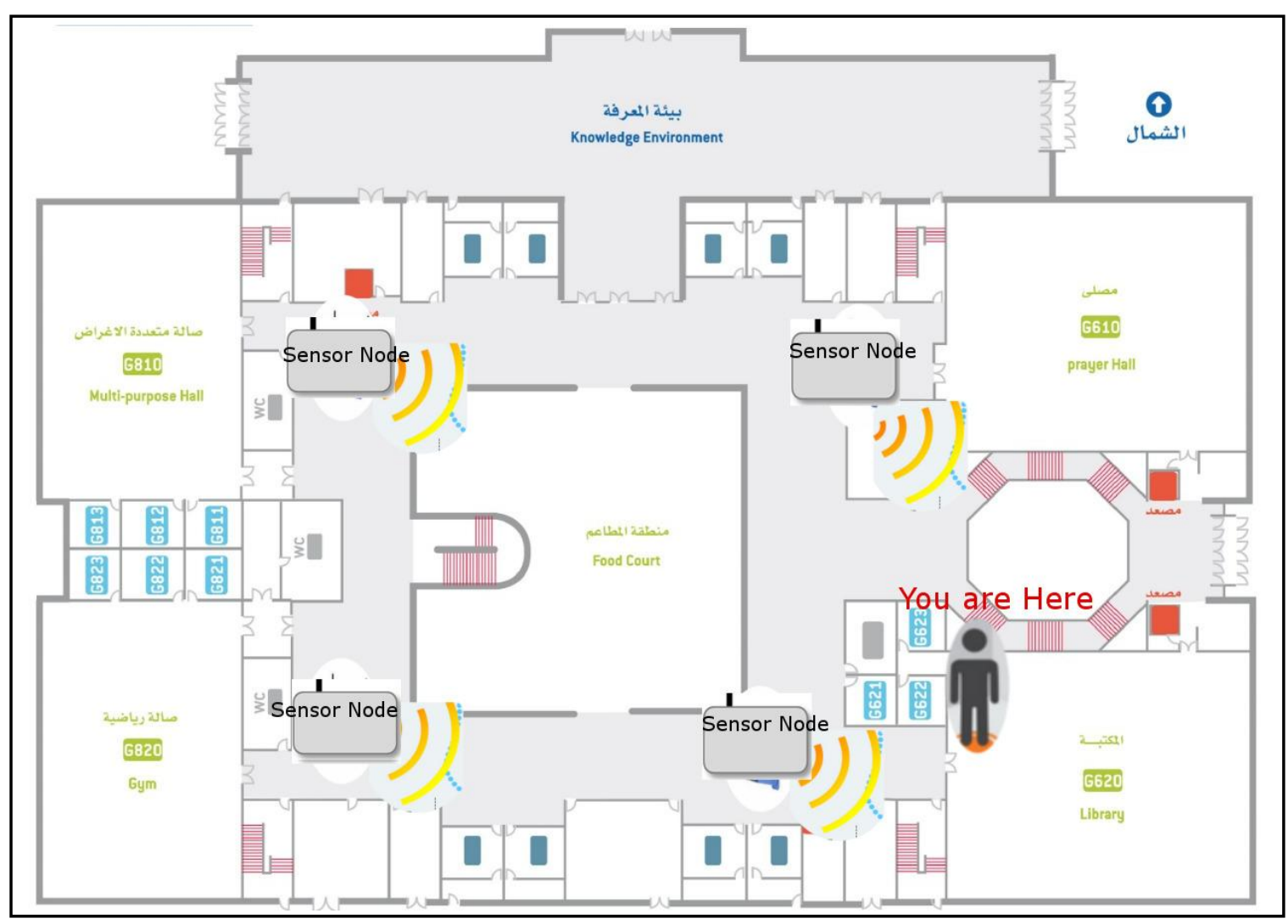

Fig:1 CFY's Floor Plan

\subsection{Meta-analysis:}

This is the use of existing research on the characteristics of different learning facilities and a combination of them to select a teaching strategy that will be effective for schools with many variables These techniques are constrained by a variety of factors, including the techniques used, accuracy, cost effectiveness, and system adoption in accordance with various protocols, as detailed in table 1 .

Table 1: Meta-Analysis of various existing localization techniques 


\begin{tabular}{|c|c|c|c|c|c|c|c|}
\hline System & $\begin{array}{l}\text { Signal } \\
\text { Type }\end{array}$ & Technique & Accuracy & Cost & $\begin{array}{l}\text { Scalabilit } \\
\mathbf{y}\end{array}$ & Pros & Cons \\
\hline Fingerprinting[5] & $\begin{array}{l}\text { Radio } \\
\text { Signals } \quad+ \\
\text { WiFi }\end{array}$ & $\begin{array}{l}\text { Ranging } \\
\text { based + } \\
\mathrm{LTF}+\mathrm{CFR}\end{array}$ & $\begin{array}{l}\text { Meter } \\
\text { Level }\end{array}$ & Low & High & $\begin{array}{l}\text { No } \\
\text { dedicated } \\
\text { devices, } \\
\text { existing } \\
\text { infrastructur } \\
\text { e, low cost }\end{array}$ & $\begin{array}{l}\text { Special } \\
\text { Purpose Array } \\
\text { Antenna, low } \\
\text { accuracy, need } \\
\text { calibration }\end{array}$ \\
\hline Fingerprinting[6] & $\begin{array}{l}\text { Radio } \\
\text { Signals + } \\
\text { WiFi }\end{array}$ & $\begin{array}{l}\text { DeepFi, } \\
\text { Greedy } \\
\text { Learning } \\
\text { Algorithm }\end{array}$ & $\begin{array}{l}\text { Meter } \\
\text { Level }\end{array}$ & Low & High & $\begin{array}{l}\text { No } \\
\text { dedicated } \\
\text { devices, } \\
\text { existing } \\
\text { infrastructur } \\
\text { e, low cost }\end{array}$ & $\begin{array}{l}\text { low accuracy, } \\
\text { need } \\
\text { calibration }\end{array}$ \\
\hline $\begin{array}{l}\text { Fingerprinting[7][8][ } \\
\text { 9] }\end{array}$ & $\begin{array}{l}\text { Radio } \\
\text { Signals + } \\
\text { WiFi }\end{array}$ & $\begin{array}{l}\text { Weighted } \\
\text { Linear } \\
\text { Regression, } \\
\text { kNN, } \\
\text { Bayesian } \\
\text { Probabilistic } \\
\text { Model }\end{array}$ & $\begin{array}{l}\text { Meter } \\
\text { Level }\end{array}$ & Low & High & $\begin{array}{l}\text { No } \\
\text { dedicated } \\
\text { devices, } \\
\text { existing } \\
\text { infrastructur } \\
\text { e, low cost }\end{array}$ & $\begin{array}{l}\text { low accuracy, } \\
\text { need } \\
\text { calibration }\end{array}$ \\
\hline Fingerprinting[10] & $\begin{array}{l}\text { WiFi } \quad+ \\
\text { Super } \\
\text { Sensitive } \\
\text { GPS }\end{array}$ & $\begin{array}{l}\text { Multi } \\
\text { Sensor } \\
\text { Fusion with } \\
\text { IMU } \\
\text { Framework, } \\
\text { Kalman } \\
\text { Filter }\end{array}$ & Low & Low & Medium & $\begin{array}{lr}\text { Low Cost, } \\
\text { can be } \\
\text { applied } & \text { on } \\
\text { big scale } & \end{array}$ & $\begin{array}{l}\text { Additional } \\
\text { Hardware }\end{array}$ \\
\hline $\begin{array}{l}\text { Radio RSS } \quad+ \\
\text { IMU[11] }\end{array}$ & $\begin{array}{l}\text { Radio } \\
\text { Signals, } \\
\text { Direction } \\
\text { Cosine } \\
\text { Matrix } \\
\text { Filter, }\end{array}$ & $\begin{array}{l}\text { IMU } \\
\text { Framework, }\end{array}$ & $\begin{array}{l}\text { Meter } \\
\text { Level }\end{array}$ & Low & High & $\begin{array}{l}\text { No } \\
\text { dedicated } \\
\text { devices, } \\
\text { existing } \\
\text { infrastructur } \\
\text { e, low cost }\end{array}$ & $\begin{array}{l}\text { Magnetic } \\
\text { Field } \\
\text { Disturbances, } \\
\text { low accuracy }\end{array}$ \\
\hline $\begin{array}{l}\text { Radio RSS, } \\
\text { Proximity[12][13] }\end{array}$ & $\begin{array}{l}\text { Particle } \\
\text { Filter } \\
\text { Algorithm, } \\
\text { Power } \\
\text { Map } \\
\text { Algorithm }\end{array}$ & $\begin{array}{l}\text { PDR, Multi } \\
\text { Sensor } \\
\text { Fusion, } \\
\text { SALA }\end{array}$ & $\begin{array}{l}\text { Moderatel } \\
\text { y High }\end{array}$ & Low & High & $\begin{array}{l}\text { Not } \quad \text { so } \\
\text { costly }\end{array}$ & $\begin{array}{l}\text { Additional } \\
\text { Hardware, } \\
\text { Impact of } \\
\text { altitude angle }\end{array}$ \\
\hline Proximity[14] & $\begin{array}{l}\text { Radio } \\
\text { Signals, } \\
\text { Quaternion } \\
\text {-Based } \\
\text { Extended } \\
\text { Kalman } \\
\text { Filter } \\
\end{array}$ & $\begin{array}{l}\text { Proximity } \\
\text { based, } \\
\text { Pedestrian } \\
\text { Tracking } \\
\text { Using IoT } \\
\text { Framework }\end{array}$ & High & Low & High & $\begin{array}{l}\text { High } \\
\text { Accuracy, } \\
\text { low cost }\end{array}$ & $\begin{array}{l}\text { Need } \\
\text { calibration, } \\
\text { Signals } \\
\text { sensitivity }\end{array}$ \\
\hline $\begin{array}{l}\text { Bluetooth Low } \\
\text { Energy[15][16][17] }\end{array}$ & $\begin{array}{l}\text { Radio } \\
\text { Signals } \\
\text { through } \\
\text { BLE }\end{array}$ & $\begin{array}{l}\text { BLE, RSS } \\
\text { Fingerprint, } \\
\text { SVM + } \\
\text { kNN }\end{array}$ & Low & Low & High & $\begin{array}{lr}\text { Low Cost, } \\
\text { can be } \\
\text { applied } & \text { on } \\
\text { big scale } & \end{array}$ & $\begin{array}{l}\text { Need } \\
\text { dedicated } \\
\text { devices, low } \\
\text { accuracy }\end{array}$ \\
\hline $\begin{array}{l}\text { Bluetooth } \quad \text { Low } \\
\text { Energy[20] }\end{array}$ & $\begin{array}{l}\text { Radio } \\
\text { Signals } \\
\text { through } \\
\text { BLE }\end{array}$ & $\begin{array}{l}\text { Triangulatio } \\
\mathrm{n} \quad \text { System, } \\
\text { DTDoA }\end{array}$ & $\begin{array}{l}\text { Meter } \\
\text { Level }\end{array}$ & Low & High & $\begin{array}{lr}\text { Low Cost, } \\
\text { can be } \\
\text { applied } & \text { on } \\
\text { big scale } & \end{array}$ & $\begin{array}{l}\text { Additional } \\
\text { Hardware } \\
\text { required, Need } \\
\text { Calibration, }\end{array}$ \\
\hline
\end{tabular}




\begin{tabular}{|c|c|c|c|c|c|c|c|}
\hline System & $\begin{array}{l}\text { Signal } \\
\text { Type }\end{array}$ & Technique & Accuracy & Cost & $\begin{array}{l}\text { Scalabilit } \\
\text { y }\end{array}$ & Pros & Cons \\
\hline RFID[21][22] & $\begin{array}{l}\text { Radio } \\
\text { Signals }+ \\
\text { Active } \\
\text { RFID }\end{array}$ & $\begin{array}{l}\text { RFID } \quad+ \\
\text { Particle } \\
\text { Filters }\end{array}$ & Moderate & $\begin{array}{l}\text { Moderatel } \\
\text { y High }\end{array}$ & Limited & $\begin{array}{l}\text { Moderate } \\
\text { Accuracy }\end{array}$ & $\begin{array}{l}\text { Additional } \\
\text { Hardware, } \\
\text { Network setup } \\
\text { and } \\
\text { synchronizatio } \\
\mathrm{n}\end{array}$ \\
\hline RFID[23][24] & $\begin{array}{l}\text { Radio } \\
\text { Signals + } \\
\text { NFC }\end{array}$ & $\begin{array}{l}\mathrm{NFC}+\mathrm{HF} \\
\mathrm{RFID,} \mathrm{QR} \\
\text { Code with } \\
\text { Dijkstra } \\
\text { Algorithm }\end{array}$ & $\begin{array}{l}\text { Moderatel } \\
\text { y High }\end{array}$ & $\begin{array}{l}\text { Moderatel } \\
\text { y High }\end{array}$ & High & $\begin{array}{l}\text { Can be } \\
\text { applied on } \\
\text { big scale and } \\
\text { moderately } \\
\text { high } \\
\text { accuracy }\end{array}$ & $\begin{array}{l}\text { Additional } \\
\text { Hardware, } \\
\text { need dense } \\
\text { nodes } \\
\text { distribution } \\
\text { and fixing and } \\
\text { synchronizatio } \\
\text { n }\end{array}$ \\
\hline Ultra-wideband[26] & $\begin{array}{l}\text { Impulse } \\
\text { radio Ultra } \\
\text { wide band } \\
\text { signal }\end{array}$ & $\begin{array}{l}\text { Ranging } \\
\text { based }\end{array}$ & High & High & High & $\begin{array}{l}\text { High } \\
\text { penetrating } \\
\text { ability, high } \\
\text { accuracy, } \\
\text { high multi- } \\
\text { path } \\
\text { resolution }\end{array}$ & $\begin{array}{l}\text { Need } \\
\text { dedicated } \\
\text { devices, } \\
\text { receivers are } \\
\text { power-hungry, } \\
\text { large scale } \\
\text { deployment of } \\
\text { expensive } \\
\text { devices }\end{array}$ \\
\hline Foglight[26] & $\begin{array}{l}\text { Coded } \\
\text { visible } \\
\text { light }\end{array}$ & $\begin{array}{l}\text { Fog } \\
\text { Computing, } \\
\text { Encoded } \\
\text { visible light }\end{array}$ & High & High & Limited & $\begin{array}{l}\text { A light } \\
\text { sensor, a } \\
\text { MCU, and a } \\
\text { wireless link } \\
\text { (optional) }\end{array}$ & $\begin{array}{l}\text { A } \\
\text { projector }\end{array}$ \\
\hline Ultrasound[27] & $\begin{array}{l}\text { Ultrasound } \\
+\quad \text { Anti } \\
\text { Bouncing } \\
\text { Filter }\end{array}$ & $\begin{array}{l}\text { Advance } \\
\text { Signal } \\
\text { Procession } \\
\text { + UEI, UEC }\end{array}$ & $\begin{array}{l}\text { High } \\
\text { (centimeter } \\
\text { ) }\end{array}$ & High & Limited & $\begin{array}{l}\text { High } \\
\text { accuracy }\end{array}$ & $\begin{array}{l}\text { Need } \\
\text { dedicated } \\
\text { devices, need } \\
\text { dense anchor } \\
\text { nodes, limited } \\
\text { scalability }\end{array}$ \\
\hline Guoguo[28] & $\begin{array}{l}\text { Modulated } \\
\text { acoustic } \\
\text { signal (17- } \\
20 \mathrm{kHz})\end{array}$ & $\begin{array}{l}\text { Passive } \\
\text { mode } \\
\text { ranging }\end{array}$ & $\begin{array}{l}\text { High }(6- \\
25 \mathrm{~cm})\end{array}$ & Low & High & $\begin{array}{l}\text { No } \\
\text { dedicated } \\
\text { device for } \\
\text { users, high } \\
\text { accuracy and } \\
\text { scalability, } \\
\text { disturbance- } \\
\text { free }\end{array}$ & $\begin{array}{l}\text { Low- } \\
\text { complexity } \\
\text { anchor nodes }\end{array}$ \\
\hline
\end{tabular}

\section{Conclusion:}

The paper presents a real-time scenario of an orientation day at CFY, as well as a detailed study and analysis of various indoor localization techniques. The study is summarized in the background with different categories of the various techniques that can be used. For the orientation day at CFY, it is focused on the best techniques that can be used in the educational sector. The meta-analysis included a detailed table that listed the various constraints along with their benefits and drawbacks. In the future, a few techniques, such as the Extended Technology Acceptance Model, will be used to adopt and evaluate acceptance approaches based on technology acceptance theoretical models. 


\section{Author Profile}

Dr. Wael Mohammad Alenazy is currently working as an Assistant Professor and Chair of Self-Development Skills at Common First Year Deanship, King Saud University, Riyadh, Saudi Arabia. He received his PhD and Master's degree from Faculty of Engineering and Information Technology, University of Technology, Sydney (UTS), Australia. His area of specialization includes Advanced ICT solutions on Smart Environments and Smart Classroom. His current area of research interests includes Smart Learning, Enhanced Smart Education, Image Processing and Augmented Reality.

\section{References}

G. Deak, K. Curran and J. Condell, "A survey of active and passive indoor localisation systems," Computer Communications, vol. 35, no. 16, pp. 1939-1954, 2012.

S. S. J. C. H. W. J. H. X. G. Z. Xiang, "A wireless LAN-based indoor positioning technology," IBM Journal of Research and Development, vol. 48, no. 5-6, p. 617, 2004.

R. B. R. Zekavat, Handbook of Position Location: Theory, Practice and Advances, NJ, USA: John Wiley \& Sons:Hoboken, 2011.

W. X. W. N. L. X. Wei Meng, "Secure and robust Wi-Fi fingerprinting indoor localization," in International Conference on Indoor Positioning and Indoor Navigation, 2011.

S. S. A. E.-H. Y. A. H. O. A. N. Amr M. Shata, "International Conference on Innovative Trends in Computer Engineering - ITCE," in Aswan University, Egypt, 2018.

L. G. S. M. S. P. Xuyu Wang, "CSI-Based Fingerprinting for Indoor Localization: A Deep Learning Approach," IEEE Transactions on Vehicular Technology, vol. 66, no. 1, pp. 763-776, January 2017.

H. N. V. Y. J. W.-S. S. A.K.M. Mahtab Hossain, "Indoor Localization Using Multiple Wireless Technologies," in IEEE International Conference on Mobile Adhoc and Sensor Systems, Italy, 8-11 October, 2007.

J. S. Q. J. Ayong Ye, "A robust location fingerprint based on differential signal strength and dynamic linear interpolation," Security and Communication Networks, vol. 9, no. 1, p. 3618-3626, 2016.

P. K. K. Kaemarungsi, "Modeling of indoor positioning systems based on location fingerprinting," in IEEE INFOCOM 2004, 7-11 March 2004.

H. K. L. C. L. R. L. P. R. G. R. C. Mohammad Zahidul H. Bhuiyan, "Tilizing building layout for performance optimization of a multi-sensor fusion model in indoor navigation," in International Conference on Localization and GNSS, 2012.

C. V. Z. Z. T. B. Z. L. A. N. José Luis, "A real-time robust indoor tracking system in smartphones," Computer Communications, vol. 117, no. 1, pp. 104-115, February 2018.

M. W. L. L. Z. M. E. W. Xiangyu Xu, "An Indoor Pedestrian Localization Algorithm Based on Multi-Sensor Information Fusion," Journal of Computer and Communications, vol. 5, no. 3, pp. 102-115, March 2017.

S. Y. T. K. H. L. S. M. K. S.-C. K. Jaehoon (Paul) Jeong, "SALA: Smartphone-Assisted Localization Algorithm for Positioning Indoor IoT Devices," Wireless Networks : The Journal of Mobile Communication, Computation and Information, vol. 24, no. 1, pp. 24-47, January 2018.

A. M. A. A. Nabil M., "Enhancing Indoor Localization Using IoT Techniques," Proceedings of the International Conference on Advanced Intelligent Systems and Informatics 2017, vol. 639, pp. 885-894, 2017.

J. A. H. C. D. M. C. P. Marco Terán, "IoT-based system for indoor location using bluetooth low energy," in 2017 IEEE Colombian Conference on Communications and Computing (COLCOM), Bagota, 2017.

P. S. Andrew Mackey, "Performance evaluation of beacons for indoor localization in smart buildings," in IEEE Global Conference on Signal and Information Processing (GlobalSIP), Montreal, Canada, 2017.

M. C.-C. L. O.-B. Jesus Lovon-Melgarejo, "Supervised learning algorithms for indoor localization fingerprinting using BLE4.0 Beacons," in IEEE Latin American Conference on Computational Intelligence (LA-CCI), Guadalajara, Mexico, November 2017.

https://www.bluetooth.com/.

R. H. Ramsey Faragher, "Location Fingerprinting With Bluetooth Low Energy Beacons," IEEE Journal on Selected Areas in Communications, vol. 33, no. 11, p. 2418-2428, November 2015.

B. D. Gunter Fischer, "Bluetooth indoor localization system," in 1st Workshop on Positioning, Navigation and Communication (Wpnc'04), 2004.

http://www.csic.es/.

A. R. J. Fernando Seco, "Smartphone-Based Cooperative Indoor Localization with RFID Technology," Sensors, vol. 18, no. 1, p. 266, 2018.

A. A. H. M. J. Z. J. W. N. Omran Al Hammadi, "Indoor Localization and Guidance Using Portable Smartphones," in IEEE/WIC/ACM International Conferences on Web Intelligence and Intelligent Agent Technology, Macau, China, 4-7 December 2012.

P. Annika, "Near Field Communication in Cell Phones," Ruhr-Universit"at Bochum, Germany, 2007.

D. S. N. W. Manh Hung V, "Indoor Navigation System for Handheld Devices," Worcester Polytechnic Institute, Massachusetts, USA, 2009. 
Q. L. P. C.-Y. S. Shang Ma, "Foglight: Visible Light-Enabled Indoor Localization System for Low-Power IoT Devices," IEEE Internet of Things Journal, vol. 5, no. 1, pp. 175-185, 2018.

S. B. C. O. L. V. M. Bruno Andò, "Smart Multisensor Strategies for Indoor Localization," in Mobility of Visually Impaired People : Fundamentals and ICT Assistive Technologies, Springer, 2018, pp. 585-595.

X. L. X. L. Kaikai Liu, "Guoguo: enabling fine-grained indoor localization via smartphone," in 11th Annual International Conference on Mobile Systems, Applications and Services, Taipei, Taiwan, June 25 - $28,2013$. 